\title{
Microdot technology for individual marking of small arthropods
}

\author{
Michael R. Whitehead and Rod Peakall \\ Evolution, Ecology and Genetics, Research School of Biology, The Australian National University, Canberra, ACT 0200, Australia
}

\begin{abstract}
Individual mark-release-recapture is an important method for gathering data on insect movement, although it is limited by the constraints of tagging small insects with individual information.

2 Microdots, originally developed for covert security applications, are small polymer discs (diameter $0.5 \mathrm{~mm}$ ) bearing up to 26 characters of information and have the potential as an alternative to the larger bee tags. In the present study, we test microdots for the individual marking of a 9-mm parasitoid wasp.

3 We individually marked 505 wasps. The recapture rate was $24 \%$ of individuals over 189 recapture events, for which $84 \%$ retained legible microdot labels. Movement was in the range $0-161 \mathrm{~m}$ with a mean displacement $21.2 \pm 2.7 \mathrm{~m}$. A captive survival experiment showed no difference in lifespan between marked and unmarked wasps.

4 The present study shows that microdots can provide an effective, durable, lowcost method for individually tagging small insects. The technique offers new opportunities by greatly expanding the capability for individually marking small insects, shifting the minimum size below that of bee tags, which is the only other manufactured option for individualized miniature marking.
\end{abstract}

Keywords Individual marking, insect behaviour, insect marking, insect movement, mark-release-recapture, thynnine.

\section{Introduction}

Marking insects in the field is essential for quantifying basic demographic properties such as population size, survival and movement, comprising data essential for the management of both pest and beneficial insects in natural and agricultural systems. For pest control, measurements of pest insect dispersal are essential for establishing the scale over which management should operate, identifying suitable habitat and assessing connectivity between populations (Mahroof et al., 2010), whereas quantifying population densities and survivorship allows the effective monitoring of management outcomes. Data on the movement of introduced control agents for biological control of pests or weeds is also crucial for predicting their spread from release points (Corbett \& Rosenheim, 1996; Bianchi et al., 2009; Moerkens et al., 2010), monitoring their populations and predicting impacts on nontarget species (Rudd \& McEvoy, 1996; Chapman et al., 2009). Conservation of beneficial insects requires dispersal data to delimit management units and the movement of pollinator species is also becoming increasingly important for restoration of pollinator services in

Correspondence: Michael R. Whitehead. Tel.: +61 261254712; fax: +61 261255573; e-mail: michael.whitehead@anu.edu.au degraded ecosystems (Menz et al., 2010), as well as assessing the risks of engineered genes escaping from geneticallymodified crops (Ellstrand, 2003).

The most common approach for quantifying insect movement is the suite of sampling and analysis techniques encompassed by mark-recapture. For these studies, marking techniques typically take one of two approaches (Hagler \& Jackson, 2001). Mass-marking techniques using paints, proteins, trace elements, fluorescent powders or dyes to quickly mark very large numbers of insects have been employed extensively for at least 75 years (Hagler \& Jackson, 2001). They cannot, however, provide individual level data. This limits their application to marking or release at certain points in the landscape and measuring diffusion from that point. The alternative approach is individualized marking, such as numbered bee tags, which offers the flexibility of marking individuals at any time or place in the field and avoids the unnatural population densities created by mass release (Bancroft \& Smith, 2005). Detailed individual level data provide the opportunity for resampling the same individuals over time, as well as measuring individual traits, such as sex or size, which might affect survival and movement (Bancroft \& Smith, 2005). Marking insects with individual tags is also usually nondestructive, unlike techniques such as trace element marking (Berry et al., 1972; Hagler \& Jackson, 2001). 
Despite these advantages, individual marking techniques are usually more time consuming and labour intensive than massmarking and are limited to larger insects able to physically bear the chosen tag.

This restriction on size has been the focus of various attempts aiming to adapt technology to the tracking of individual insects. The ongoing development of harmonic radar and radio technology for tracking insects has proved promising (Mascanzoni \& Wallin, 1986; Riley et al., 1996; O'Neal et al., 2004; Sword et al., 2005; Wikelski et al., 2010), although the technology remains costly and is still limited to larger insects (O'Neal et al., 2004). Passive radio-frequency identification chips have now been miniaturized sufficiently to tag bees (Pahl et al., 2011), paper-wasps (Sumner et al., 2007) and ants (Robinson et al., 2009); however, the chips are required to come into close proximity with the chip reader, which makes them unsuitable for some systems and potentially expensive (Moreau et al., 2011).

In the present study, we describe a novel, simple and cost effective approach for the individualized mark-releaserecapture of small insects, which combines traditional marking methods with new microdot technology. Microdots, developed for covert security and authentication applications, are polymer discs manufactured to bear a unique identifying code. For insect marking, they are analogous to bee tags and the labels developed for chrysomelid beetles (Piper, 2003). Bee tags with diameter of $2.5 \mathrm{~mm}$ are obviously limited to insects with a single segment larger than $2.5 \mathrm{~mm}$, which makes them unsuitable for use on most insects with a total length smaller than approximately $10 \mathrm{~mm}$, and especially for insects with slender bodies. The small size of microdots (diameter $0.5 \mathrm{~mm}$, weight $25 \mu \mathrm{g}$ ) not only expands the lower size limit for individual insect marking, but also should make them less disruptive to insect flight than larger tags. Further advantages include the capacity to carry more information than bee tags with customizable flexibility, such that researchers may have any combination of up to 26 characters inscribed upon them. To test microdots in an experimental mark-release-recapture study, we applied them to quantify the movement of the parasitoid thynnine wasp Neozeleboria cryptoides (Smith) (Hymenoptera, Tiphiidae).

The biology of the thynnines is almost unknown, although it is assumed that they parasitize wood or soil-dwelling larvae of ants and beetles (Ridsdill Smith, 1970; Brown, 1998), which may make them a potential biological control agent for scarab larvae (Ridsdill Smith, 1970). The females are wingless and dwell in the soil, only surfacing to mate with males. The male wasps are strong fliers (average length $9 \mathrm{~mm}$, weight $16 \mathrm{mg}$ ) (Schiestl, 2004). A 2008 pilot study marking individuals with correction fluid showed that, despite being highly mobile, $N$. cryptoides rarely moved more than $25 \mathrm{~m}$ between recaptures, with a maximum displacement recorded of $85 \mathrm{~m}$ (M. Whitehead, unpublished data).

In the present study, we report the development and implementation of a novel application of microdot technology as a method for individually marking small wasps. As proof of concept, we apply the technique to measuring individual movement in a population of $N$. cryptoides. We assess the efficacy, benefits and limitations of the technique and conclude by considering new opportunities for application of the method.

\section{Materials and methods}

\section{Mark-release-recapture}

Field work was conducted in open Eucalyptus woodland in Canberra, Australia, which was chosen as a result of the known abundance of $N$. cryptoides. We attracted male wasps using previously described techniques (Schiestl et al., 2003; Schiestl \& Peakall, 2005; Peakall et al., 2010), whereby patrolling male $N$. cryptoides wasps were attracted to synthetic chiloglottone1 (Franke et al., 2009) when presented on a plastic pin-head dummy and captured in a net. To implement microdots for mark-release-recapture, we needed to both attach the dots and recognize recaptures. Correction fluid and nail varnish have been used widely in insect-marking studies without toxicity (White, 1970; Wineriter \& Walker, 1984; Peakall, 1990; Piper, 2003; St Pierre et al., 2005); therefore, they were both used as a colour mark and adhesive in the present study. The use of coloured adhesives was important for quickly recognizing recaptures and providing a background contrast against which to read the microdot codes. We painted wasps with one of six coloured adhesives to which microdots were applied before the adhesive dried (Fig. 1). The microdots were applied with a plastic pipette-tip to which they adhered when the tip was statically charged on clothing. We ordered 100 uniquely numbered batches manufactured by DataDot Technology (http://www.datadotdna.com), with each batch containing 1000 microdots, costing approximately $\$ 15$ (AUD) per batch. For the six coloured adhesives used, we had 100 unique codes for individual marking, giving a total of 600 unique labels and the capacity to tag several thousand wasps.

Data collection was confined to periods of wasp activity, which were necessarily warm $\left(>19{ }^{\circ} \mathrm{C}\right)$, fine days without strong wind, resulting in a sampling window of between 11.00 and $17.00 \mathrm{~h}$ on any suitable day. Phase one (mark phase; 28 August 2009 to 14 September 2009) of the study involved the capture, marking, release and recapture of marked wasps at nine fixed bait stations (two four-point rectangular arrays of $15 \times 30 \mathrm{~m}$ separated by approximately $85 \mathrm{~m}$ and one point $20 \mathrm{~m}$ from the nearest array; forming a polygon of $299 \mathrm{~m}^{2}$ ). This was intended to quickly establish a large proportion of marked individuals from known locations. Phase two (roam phase; 15 September 2009 to 25 September 2009) consisted of random sampling across the site in the form of timed recapture trials. The roam phase sampling area was delineated by a habitat boundary of grassland where there were few wasps. A single recapture trial lasted for $5 \mathrm{~min}$, with all males approaching the synthetic pheromone being captured and scored as either an unmarked capture or a recapture event where there was evidence of a previous mark adhering to the cuticle. Microdots on recaptured wasps were read with a handheld $50 \times$ pen-microscope (ProSciTech, Australia) and position was recorded with a Global Positioning System unit. The baits were transported between trials in a sealed container. Throughout both phases of the study, wasps that were recaptured carrying 




Figure 1 Anterior of male Neozeleboria cryptoides thorax showing attached microdot. Image credit: (c) Commonwealth Scientific and Industrial Research Organisation.

adhesive remnants but lost microdots were refreshed with a new paint and microdot combination before re-release.

\section{Survival experiment and statistical analysis}

To assess potential toxicity of the marking technique on wasps, we kept both marked $(n=51)$ and unmarked $(n=27)$ wasps under standard laboratory conditions fed on sugar solution. The two groups were housed together and, each day for 40 days, data on mortality were recorded. Difference in survivorship curves between the treatment and control groups was tested by two Wilcoxon test methods implemented in R software; a log-rank test that assumes constant proportional hazard between groups and a Gehan-Breslow weighted Wilcoxon test that weights deaths earlier in time more heavily (Klein \& Moeschberger, 2003). This latter test was considered appropriate for detecting the immediate or short-term deleterious effects of marking the wasps. Approximate abundance was estimated by fitting a Poisson log-normal mark-resight model to the recapture data as previously described by McClintock and White (2009). This was implemented in MARK, version 2.0 (White \& Burnham, 1999), assuming an open population and no heterogeneity in capture probability among individuals (M. Whitehead, unpublished data).

\section{Results}

We marked a total of 505 individual wasps in 26 person/h over 9 days during the mark phase of the study. The roam phase effort totaled 17.2 person/h in 9 days over 214 recapture trials. In total, we recorded 189 recapture events through both phases of the study. Of these, 30 (16\%) recaptures were of wasps that had lost their microdot and could not be individually identified. The remaining 159 recapture events for which individual data were recorded were broken down into 87 individuals recorded for single recaptures, 31 individuals recaptured twice, four individuals recaptured three times, and a single individual recaptured four times. Altogether, there were 123 individual wasps recaptured, representing $24 \%$ of the total marked pool of animals.

As an indicator of survival, the mean \pm SD time between first and last captures for all recaptured individuals was $8.8 \pm$ 5.9 days (range 1-24 days). Release to recapture distances varied from $0-161$ and $0-150 \mathrm{~m}$ for the mark and roam phases, respectively. Mean displacement was $15.5 \pm 3.4 \mathrm{~m}$ $(n=81$, median $=0)$ for mark phase recaptures and $27 \pm$ $4.1 \mathrm{~m}(n=78$, median $=14.8 \mathrm{~m})$ for roam phase recaptures. The captive survival experiment resulted in similar mean \pm SE survival for marked (11.8 \pm 2.1 days $)$ and unmarked wasps (13.7 \pm 1.5 days) and the survival curves did not differ significantly $\left(\log\right.$-rank $\chi^{2}=0.1$, d.f. $=1, \mathrm{P}=0.763$; Wilcoxon Gehan statistic $=3.419, \mathrm{P}=0.181$ ). The Poisson log-normal model derived mean \pm SD population size for the beginning of the mark phase was estimated to be $3454( \pm 302)$ individuals. This is broadly within the range of expectation given the mean \pm SD proportion of marked to unmarked captures of $0.12 \pm 0.23$ and the total marked insect pool of 505 individuals.

\section{Discussion}

The technique allowed us to uniquely label 505 individual wasps in the field at a rate of 20 individuals per person/h. This rate of marking includes the time taken to attract, net and mark wasps, record data and move between subsequent baiting sites. It is therefore a reasonably labour-intensive process; however, marking with any unique identifying tag (e.g. bee tags, radio-frequency identification chips) will require similar effort. Durability was demonstrated by 189 recapture events, with $84 \%$ of recaptured insects bearing a legible microdot label, and legible recaptures collected up to 24 days after initial marking. Although the lifespan or flight time of adult wasps in the wild is unknown, the availability of wasps is restricted to 4-5 weeks per year, suggesting, in conjunction with the results of the present study, a flight time for individuals of 3-4 weeks. The overall mean survival for captive wasps was 12.5 days after capture and one marked individual remained alive at day 40 when the study was stopped. Wasp movement documented in the present study was in the range predicted by a 2008 pilot study that used only correction fluid and nail varnish to mark individuals (M. Whitehead, unpublished data), which suggests that the additional treatment of the microdot attachment has not affected behaviour. The present study relies on a sexual response to recapture males and the rate of recapture $(24 \%)$ 
suggests that marking has not negatively impeded wasp matesearch behaviour. As a result of the largely fossorial lifestyle of the female thynnine, it is rare to find mating wasps in the field, although, in 2009, the only observed coupling was with a marked male, showing that marking does not prevent subsequent successful mating.

The findings of the present study show that microdots can provide a simple, relatively cost effective and useful method of individualized marking. Microdots could enable mark-release-recapture studies in a wider range of insects than presently possible, shifting the minimum size range below that of bee tags, which is the only other manufactured option for miniaturized marking. Their small size makes them ideal for any small invertebrate with a hard surface larger than approximately $1 \mathrm{~mm}$ in diameter for attachment. Limitations at this size range involve the method of adhesion because glues and paints can be difficult to apply with such precision and smaller areas of application will likely require adhesives of higher visibility. The loss of some microdots (16\% of recaptures were missing microdots) shows that there is scope for using adhesives that improve label retention. Microdots attached with nail varnish were disproportionately represented in the total of cases where microdots were lost (half of losses but only one sixth of marked insects); therefore, correction fluid proved to be the most effective adhesive used in the present study. The tendency of these materials to flake or chip from insect cuticles has been reported previously (Wineriter \& Walker, 1984), although possible alternatives might be found in the range of cyanoacrylate glues already employed to attach harmonic radar tags to insects (Boiteau et al., 2009) provided that the glue can be blended with colour to aid in the detection and readability of the microdot.

Pest management, insect conservation and land management of natural and agro-ecosystems provide many scenarios for employing miniaturized individual tagging. Microdots provide another tool for exploring insect movement in these contexts, especially for parasitoid wasps and pollinating bees, as well as flies that are smaller than the honeybee, for which the present study serves as proof of concept. Future tests are needed to evaluate applications for marking more challenging species, such as burrowing insects or those with hairy cuticles. There may also be opportunities to utilize this technology outside of insects. Aquatic invertebrates such as molluscs and crustaceans with hard shells could be tagged if water-proof adhesives are used. Small seeds could potentially be labelled with microdots to trace dispersal, and the technology might even be able to be exploited as a pollen analogue in studies of pollen dispersal. Effective markers should be durable, low-cost, nontoxic, easily applied, clearly identifiable and avoid interfering with the animal's behaviour (Hagler \& Jackson, 2001). We conclude that microdots show promise as an effective new marking technique for any future study employing individual tags.

\section{Acknowledgements}

We thank DataDot Technology (http://www.datadotdna.com), Natalie Banks for photography assistance in Figure 1 and Andrew Whitehead for discussion that led to this research.
Michael Whitehead was supported by an Australian National University PhD Scholarship and an Australian Pacific Science Foundation grant (APSF 08/6). Rod Peakall was supported by an Australian Research Council project (DP045137).

\section{References}

Bancroft, J.S. \& Smith, M.T. (2005) Dispersal and influences on movement for Anoplophora glabripennis calculated from individual mark-recapture. Entomologia Experimentalis et Applicata, 116, $83-92$.

Berry, W.L., Stimmann, M.W. \& Wolf, W.W. (1972) Marking of native phytophagous insects with rubidium: a proposed technique. Annals of the Entomological Society of America, 65, 236-238.

Bianchi, F., Schellhorn, N.A. \& Van Der Werf, W. (2009) Predicting the time to colonization of the parasitoid Diadegma semiclausum: the importance of the shape of spatial dispersal kernels for biological control. Biological Control, 50, 267-274.

Boiteau, G., Meloche, F., Vincent, C. \& Leskey, T.C. (2009) Effectiveness of glues used for harmonic radar attachment and impact on survival and behavior of three insect pests. Environmental Entomology, 38, 168-175.

Brown, G.R. (1998) Revision of the Neozeleboria cryptoides species group of thynnine wasps (Hymenoptera: Tiphiidae): pollinators of native orchids. Australian Journal of Entomology, 37, 193-205.

Chapman, A.V., Kuhar, T.P., Schultz, P.B. \& Brewster, C.C. (2009) Dispersal of Trichogramma ostriniae (Hymenoptera: Trichogrammatidae) in potato fields. Environmental Entomology, 38, $677-685$.

Corbett, A. \& Rosenheim, J.A. (1996) Quantifying movement of a minute parasitoid, Anagrus epos (Hymenoptera: Mymaridae), using fluorescent dust marking and recapture. Biological Control, 6, 35-44.

Ellstrand, N.C. (2003) Current knowledge of gene flow in plants: implications for transgene flow. Philosophical Transactions of the Royal Society B, Biological Sciences, 358, 1163-1170.

Franke, S., Ibarra, F., Schulz, C.M. et al. (2009) The discovery of 2,5dialkylcyclohexan-1,3-diones as a new class of natural products. Proceedings of the National Academy of Sciences of the United States of America, 106, 8877-8882.

Hagler, J.R. \& Jackson, C.G. (2001) Methods for marking insects: current techniques and future prospects. Annual Review of Entomology, 46, 511-543.

Klein, J.P. \& Moeschberger, M.L. (2003) Survival analysis: techniques for censored and truncated data, 2nd edn. Springer, New York, New York.

Mahroof, R.M., Edde, P.A., Robertson, B., Pucketfe, J.A. \& Phillips, T.W. (2010) Dispersal of Rhyzopertha dominica (Coleoptera: Bostrichidae) in different habitats. Environmental Entomology, 39, 930-938.

Mascanzoni, D. \& Wallin, H. (1986) The harmonic radar: a new method of tracing insects in the field. Ecological Entomology, 11, $387-390$

McClintock, B.T. \& White, G.C. (2009) A less field-intensive robust design for estimating demographic parameters with mark-resight data. Ecology, 90, 313-320.

Menz, M.H.M., Phillips, R.D., Winfree, R., Kremen, C., Aizen, M.A., Johnson, S.D. \& Dixon, K.W. (2010) Reconnecting plants and pollinators: challenges in the restoration of pollination mutualisms. Trends in Plant Science, 16, 4-12.

Moerkens, R., Leirs, H., Peusens, G. \& Gobin, B. (2010) Dispersal of single- and double-brood populations of the European earwig, Forficula auricularia: a mark-recapture experiment. Entomologia Experimentalis et Applicata, 137, 19-27. 
Moreau, M., Arrufat, P., Latil, G. \& Jeanson, R. (2011) Use of radiotagging to map spatial organization and social interactions in insects. Journal of Experimental Biology, 214, 17-21.

O’Neal, M.E., Landis, D.A., Rothwell, E., Kempel, L. \& Reinhard, D. (2004) Tracking insects with harmonic radar: a case study. American Entomologist, 50, 212-218.

Pahl, M., Zhu, H., Tautz, J. \& Zhang, S. (2011) Large scale homing in honeybees. PLoS ONE, 6, e19669, DOI: 10.1371/journal.pone. 0019669 .

Peakall, R. (1990) Responses of male Zaspilothynnus trilobatus Turner wasps to females and the sexually deceptive orchid it pollinates. Functional Ecology, 4, 159-167.

Peakall, R., Ebert, D., Poldy, J., Barrow, R.A., Francke, W., Bower, C.C. \& Schiestl, F.P. (2010) Pollinator specificity, floral odour chemistry and the phylogeny of Australian sexually deceptive Chiloglottis orchids: implications for pollinator-driven speciation. New Phytologist, 188, 437-450.

Piper, R.W. (2003) A novel technique for the individual marking of smaller insects. Entomologia Experimentalis et Applicata, 106, $155-157$.

R Core Development Team (2011) R: A Language and Environment for Statistical Computing. R Foundation for Statistical Computing, Austria [WWW document]. URL http://www.R-project.org.

Ridsdill Smith, T.J. (1970) The biology of Hemithynnus hyalinatus (Hymenoptera: Tephiidae), a parasite on scarabaeid larvae. Journal of the Australian Entomological Society, 9, 183195.

Riley, J.R., Smith, A.D., Reynolds, D.R. et al. (1996) Tracking bees with harmonic radar. Nature, 379, 29-30.

Robinson, E., Richardson, T., Sendova-Franks, A., Feinerman, O. \& Franks, N. (2009) Radio tagging reveals the roles of corpulence, experience and social information in ant decision making. Behavioral Ecology and Sociobiology, 63, 627-636.
Rudd, N.T. \& McEvoy, P.B. (1996) Local dispersal by the cinnabar moth Tyria jacobaeae. Ecological Applications, 6, 285-297.

Schiestl, F.P. (2004) Floral evolution and pollinator mate choice in a sexually deceptive orchid. Journal of Evolutionary Biology, 17, $67-75$.

Schiestl, F.P. \& Peakall, R. (2005) Two orchids attract different pollinators with the same floral odour compound: ecological and evolutionary implications. Functional Ecology, 19, 674-680.

Schiestl, F.P., Peakall, R., Mant, J.G., Ibarra, F., Schulz, C., Franke, S. \& Francke, W. (2003) The chemistry of sexual deception in an orchid-wasp pollination system. Science, 302, 437-438.

St Pierre, M.J., Hendrix, S.D. \& Lewis, C.K. (2005) Dispersal ability and host-plant characteristics influence spatial population structure of monophagous beetles. Ecological Entomology, 30, 105-115.

Sumner, S., Lucas, E., Barker, J. \& Isaac, N. (2007) Radio-tagging technology reveals extreme nest-drifting behavior in a eusocial insect. Current Biology, 17, 140-145.

Sword, G.A., Lorch, P.D. \& Gwynne, D.T. (2005) Insect behaviour: migratory bands give crickets protection. Nature, 433, 703 .

White, E.G. (1970) A self-checking coding technique for markrecapture studies. Bulletin of Entomological Research, 60, 303-307.

White, G.C. \& Burnham, K.P. (1999) Program MARK: survival estimation from populations of marked animals. Bird Study, 46 (Suppl), 120-138.

Wikelski, M., Moxley, J., Eaton-Mordas, A. et al. (2010) Large-range movements of neotropical orchid bees observed via radio telemetry. PLOS ONE, 5, e10738.

Wineriter, S.A. \& Walker, T.J. (1984) Insect marking techniques: durability of materials. Entomological News, 95, 117-123.

Accepted 7 August 2011

First published online 20 September 2011 
